\title{
PREPARATION AND PRELIMINARY EVALUATION OF NOVEL $\beta$-CYCLODEXTRIN/IUDR PRODRUG FORMULATIONS
}

\author{
Xiao-Hong (Jennifer) Yang ${ }^{1,2}$, Shradha Singh ${ }^{1}$, Jim Diakur $^{1 \Psi}$ and Leonard I. Wiebe ${ }^{1,2^{\star}}$ \\ ${ }^{1}$ Faculty of Pharmacy \& Pharmaceutical Sciences, University of Alberta, Edmonton, and ${ }^{2}$ PET Centre, Cross Cancer \\ Institute, Edmonton, Alberta, Canada.
}

Received, April 25, 2008; Revised, May 20, 2008; Accepted, May 20, 2008; Published, May 22, 2008.

\begin{abstract}
PURPOSE. Iododeoxyuridine (IUdR) has a very short in vivo half-life and consequently achieves low target-tissue concentrations with concomitant lower efficacy than would be predicted from in vitro studies. This work reports the preparation of IUdR: $\beta$ cyclodextrin $(\beta-\mathrm{CyD})$ inclusion complexes designed to reduce in vivo inactivation of IUdR. METHODS. IUdR was derivatized with either 1adamantanecarbonyl chloride or 4-(1-adamantylcarbamoyl)butanoic acid, to prepare 5'-O-(1adamantoyl)-5-iodo-2'-deoxyuridine 1 and 5 '- $O$-(4(1-adamantylcarbamoyl)butoyl)-5-iodo-2'-deoxyuridine 4, respectively. $\beta$-CyD complexes 5 and $\mathbf{6}$ were formed by vigorous stirring of 1:1 solutions of $\beta-\mathrm{CyD}$ and 1 or 4 , respectively, in $\mathrm{D}_{2} \mathrm{O}$ under argon. Complexation was inferred from DSC, powder x-ray diffractometry and NMR spectrometry. The dissociation of $\mathbf{5}$ in water and under cholesterol challenge, and the effect of complexation on the stability of $\mathbf{1}$ was determined by incubation in plasma. RESULTS. IUdR coupling with adamantanecarbonyl chloride proceeded smoothly to afford $1(69 \%)$ and the disubstituted derivative, 3',5'-di-O-(1-adamantoyl)-5iodo-2'-deoxyuridine 2 (8\%); 4 was obtained in 42 $\%$ yield. The formation of $1: 1$ complexes 5 and $\mathbf{6}$ was inferred from NMR chemical shift data. In serum, 1 was $90 \%$ hydrolyzed to IUdR in $30 \mathrm{~min}$, compared to $10 \%$ hydrolysis of $\mathbf{1}$ to IUdR when from complex 5. CONCLUSIONS. Inclusion complexes were formed between $\beta-\mathrm{CyD}$ and adamantamine-IUdR conjugates at 1:1 molar ratios.

The complex 5 was resistant to dissociation by cholesterol challenge, and $\mathbf{5}$ was more slowly converted to IUdR than non-complexed 1. In vivo studies are required to further exploit the $\beta-C y D$ inclusion complex approach for improved delivery of nucleoside derivatives.
\end{abstract}

\section{INTRODUCTION}

The application of halogenated pyrimidine nucleosides to the measurement of cell proliferation and to induce radiation sensitization is well established $(1,2)$. Biologically, the halogensubstituted analogues of thymidine (TdR), such as 5-iodo-2'-deoxyuridine (IUdR), compete with TdR for phosphorylation and are subsequently incorporated into DNA. When labeled with radioisotopes of iodine, IUdR is suitable for radiodiagnosis and radiotherapy (3-5). There is compelling evidence from loco-regional administration studies that radiolabelled IUdR is effective for the treatment of tumors characterized by high cell proliferation kinetics, such as liver tumors resulting from the metastasis of colorectal cancer (6), and high grade malignant gliomas (7). In fact, when radiolabeled with an Auger electron emitter such as ${ }^{123} \mathrm{I}$ or ${ }^{125} \mathrm{I}$, IUdR exhibits substantial in vitro toxicity when taken up by mammalian cells (8). Although the intranuclear incorporation rate of IUdR by dividing cells in vitro is high, IUdR undergoes rapid in vivo metabolic degradation, and its short half-life in vivo (5-7 minutes)(9) severely hampers its clinical utility.

Like many cell cycle dependent drugs, IUdR is incorporated during $\mathrm{S}$ phase to synthesize DNA in preparation for cell duplication. A critical local concentration must be maintained for adequate uptake, usually at the cost of systemic toxicity. Unfortunately, the rapid metabolic degradation of IUdR in vivo militates against protracted elevated blood levels even when high doses are administered.

Correspondence Author: Professor Leonard I Wiebe, 1807 PET Centre, Cross Cancer Institute, Edmonton, Email: leonard.wiebe@,ualberta.ca 
A formulation which would improve the biological stability of IUdR should therefore facilitate its incorporation into DNA. At the same time, any free compound should be rapidly cleared in order to reduce systemic toxicity by minimizing the dose to normal dividing cells (i.e., bone marrow and intestine) and the thyroid (for radioiodinated IUdR). Cyclodextrins (CyDs) are well suited for oral drug delivery applications (10), but potential toxicity and sheer bulk have precluded their utilization for parenterally-delivered drugs. In the case of radiotherapeutic drugs, however, where the chemical (bulk) dose is very small, CyD toxicity would not be an issue. Due to their intrinsic cyclic nature, CyDs are metabolized at much slower rates than their open chain analogs. In terms of molecular architecture, CyDs can be viewed as hollow truncated conical cylinders with a hydrophilic outer surface inscribing a hydrophobic internal cavity. The cavity sizes for the commonly available $\alpha-, \beta$ and $\gamma$-CyD are 4.9, 6.2 and $7.9 \AA$, respectively (11), dimensions which are ideal for the inclusion of low molecular weight lipophilic drugs. This ability to form inclusion complexes has been exploited to alter the chemical and physical properties of guest (drug) molecules, to effect improved water solubility, prolong in vivo stability, reduce toxicity and irritancy, and improve bioavailability (12). Release of the guest molecule is governed by dissociation, and therefore selective chemical modifications can be employed to control equilibrium thermodynamics, and thus release rate.

This paper reports the synthesis of IUdR prodrugs for complexation with $\beta-\mathrm{CyD}$, with the objective of improving the efficacy of intravenously administered IUdR. Direct complexation of nucleosides and nucleotides with cyclodextrin hosts has been previously reported $(13,14)$, but our attempts to complex IUdR with various CyDs offered no evidence of complexation-induced chemical shifts in the NMR spectra of either the host or guest molecule, thus failing to confirm that inclusion had occurred. The primary task in the current work, therefore, was to address the issue of the restricted host cavity size of $\beta-C y D$ and dissociation of the inclusion complex. To this end, the strategy for preparing prodrugs equipped with a high affinity ligand for the $\beta$-CyD cavity, namely the adamantane skeleton, has been explored.
The high binding affinity of the adamantane skeleton for $\beta$-CyD is well documented (15-18), yet the approach of utilizing this ligand for general drug delivery remains relatively unexplored. In the current work, adamantane guest ligands were selected on the basis that they are available with either a carboxyl or amino functionality, and therefore are amenable to standard peptide chemistry. This allows for the convenient assembly of prodrugs from the parent drug via an ester or amide bond, which is bio-hydrolyzable and thereby ensures the release of the free drug in vivo. The preparation of two IUdR-adamantane prodrugs connected via a short and a long bio-cleavable linker arm, and their formulation with $\beta-\mathrm{CyD}$, are now reported.

\section{RESULTS}

The approach to the synthesis of IUdR-adamantane prodrugs $\mathbf{1}$ and $\mathbf{4}$ is shown in Scheme 1. Thus, a solution of IUdR in pyridine was treated with freshly prepared 1-adamantanecarbonyl chloride (1.4 equiv) to give esters 1 and 2 in $69 \%$ and $8 \%$ yield, respectively, after column chromatography over silica gel.

The preparation of an IUdR prodrug with a longer linker arm required modification of 1adamantanamine hydrochloride. This material was treated with glutaric anhydride (1.5 equiv) in $1: 1$ pyridine/chloroform at $75{ }^{\circ} \mathrm{C}$. Adamantane derivative 3 was obtained in $81 \%$ yield after aqueous work-up and trituration with chloroform. Dicyclohexylcarbodiimide mediated coupling of $\mathbf{3}$ to IUdR in pyridine at $70{ }^{\circ} \mathrm{C}$ afforded IUdR prodrug $4(42 \%)$ after purification on silica gel.

Both 1 and $\mathbf{4}$ were found to be poorly water soluble. The aqueous solubility of $\mathbf{1}$ was determined to be $26 \mu \mathrm{g} / \mathrm{mL}$ at $25{ }^{\circ} \mathrm{C}$, with an octanol-water partition coefficient $(\log \mathrm{P})$ of 1.91 (calculated 1.85) and an octanol-phosphate buffer partition coefficient of 1.97. The solubility of $\mathbf{1}$ in the presence of $\beta$-CyD determined a water solubility of $8.26 \mathrm{mg} / \mathrm{mL}$ (Fig. 1) with an $A_{L}$ phase solubility diagram.

The formation of 1:1 inclusion complexes between $\beta$-CyD and IUdR derivatives $\mathbf{1}$ and $\mathbf{4}$ was carried out at $50-60{ }^{\circ} \mathrm{C}$ for $30 \mathrm{~min}$ with vigorous agitation. 

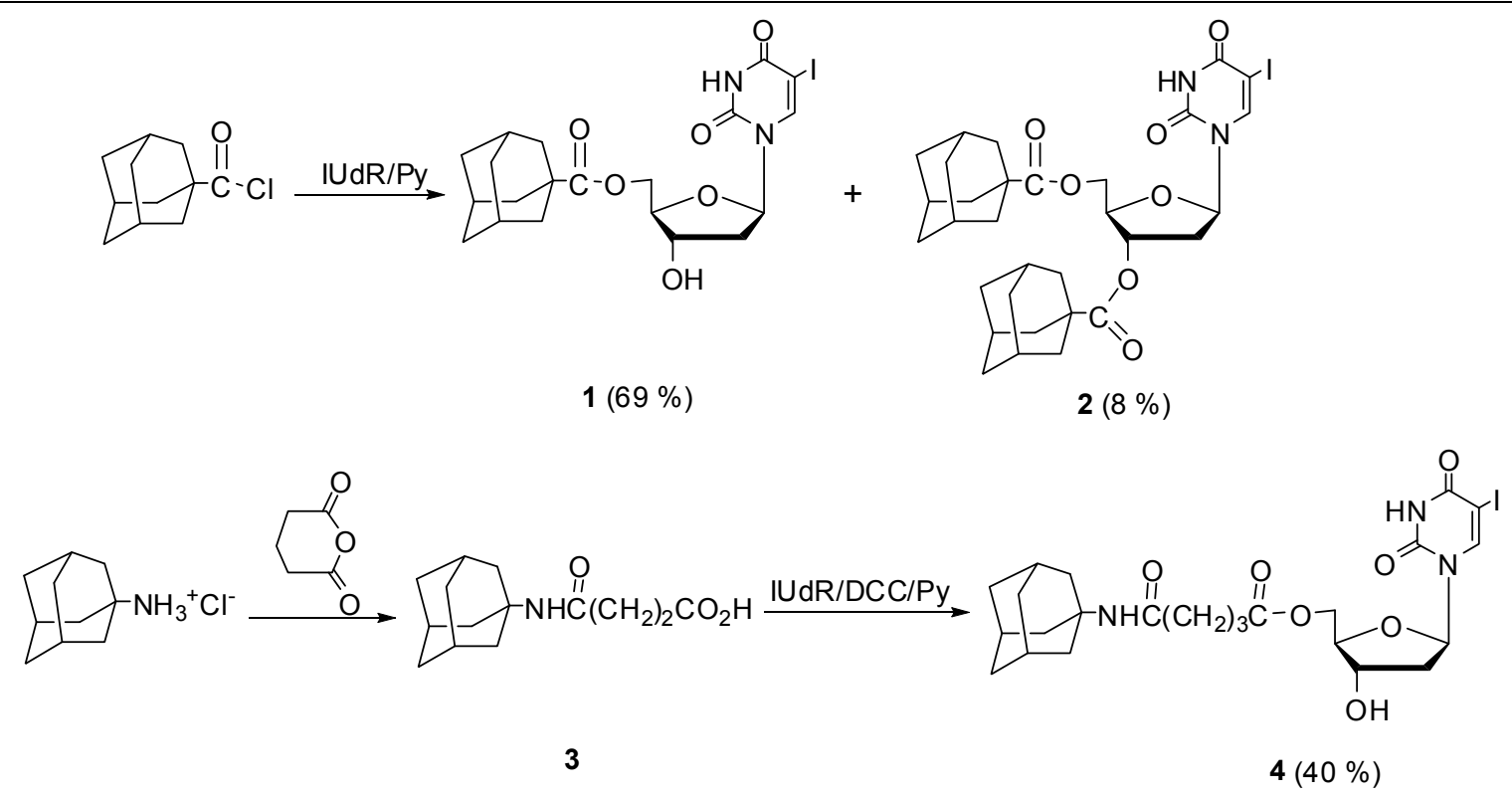

Scheme 1. Synthesis of IUdR-adamantane derivatives.

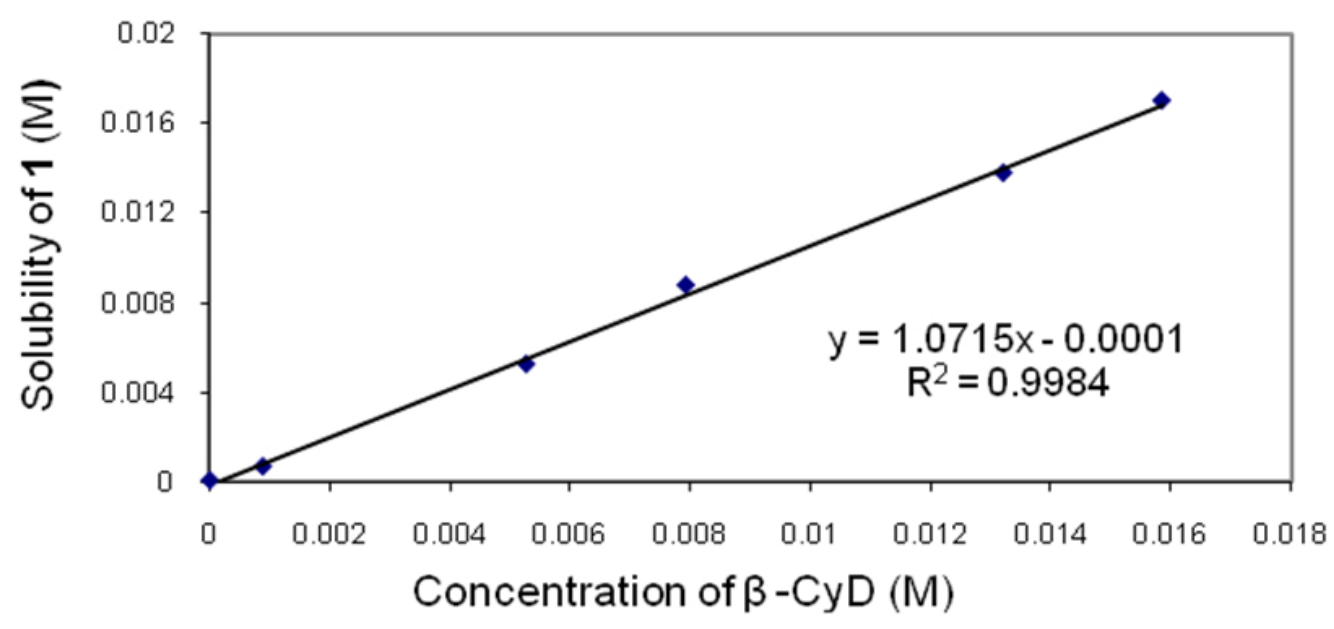

Figure 1. Solubility of 1 as a function of $\beta$-CyD concentration. Calculated data were derived using Excel (Microsoft).

The non-complexed prodrug was then removed by filtration prior to analysis of the complex by differential scanning calorimetry (DSC), powder Xray diffraction and ${ }^{1} \mathrm{H}$ NMR. DSC scans of $1, \beta$ $\mathrm{CyD}, \mathbf{1}$ and $\beta$-CyD mixed and complex $\mathbf{5}$ were obtained in the temperature range from $40-250{ }^{\circ} \mathrm{C}$ (data not shown). The thermogram of 1 featured a single exothermic peak at $208{ }^{\circ} \mathrm{C}$ whereas $\beta$-CyD had a very broad transition range from $70-180{ }^{\circ} \mathrm{C}$ and a small endothermic peak at $220{ }^{\circ} \mathrm{C}$. The mixture of 1 and $\beta$-CyD produced two endothermic peaks $\left(220^{\circ} \mathrm{C}\right.$ and $\left.227^{\circ} \mathrm{C}\right)$ and an exothermic peak at $240^{\circ} \mathrm{C}$. The complex $\mathbf{5}$ had an endothermic peak at $235^{\circ} \mathrm{C}$. Prodrug 1 decomposed at its endothermic peak temperature $\left(208^{\circ} \mathrm{C}\right)$.

Further evidence of complex formation was obtained from X-ray power diffraction studies. The $\mathrm{X}$-ray powder diffractogram of the physical mixture was simply the superposition of each component (1 and $\beta$-CyD) with the peaks having lower intensity, whereas the diffractogram of $\mathbf{5}$ consisted of a single broad peak of moderate intensity (data not shown). 
The proton NMR spectra of complexes $\mathbf{5}$ and $\mathbf{6}$ provided the strongest evidence of complex formation, inferring the presence of a 1:1 mixture of host $\beta$-CyD and guest 1 by proton resonance integration (data not shown). Formation of inclusion complexes $\mathbf{5}$ and $\mathbf{6}$ was further confirmed by the presence of upfield shifts for H-3 and H-5 (0.08 and $0.09 \mathrm{ppm}$, respectively) for the corresponding complexes 5 and $\mathbf{6}$ (Scheme 2).

The dissociation of complex $\mathbf{5}$ in aqueous solution (1.2 and $6.2 \mathrm{mM}$ ) was determined as a function of time at $37^{\circ} \mathrm{C}$ (Fig. 2). Aliquots taken at prescribed intervals over $3 \mathrm{~h}$ were extracted with octanol and the octanol phase was assayed for $\mathbf{1}$ by HPLC. The regression lines for the semi-log plots of the $0-3 \mathrm{~h}$ data are described by the equations $\mathrm{y}=$ $-0.6178 \mathrm{x}+90.908, \mathrm{R}^{2}=0.9554$ and $\mathrm{y}=-0.6143 \mathrm{x}+$ $97.408, \mathrm{R}^{2}=0.9756$; dissociation half-lives were 40 and $65 \mathrm{~min}$, respectively, based on 3-h data.

The stability of $\mathbf{5}$ in the presence of cholesterol, a major, high-affinity physiological ligand for $\beta-\mathrm{CyD}$ was determined using this simple experimental approach, using various concentrations of cholesterol in the octanol phase of the two-phase system. The presence of cholesterol had no discernable influence on the release of $\mathbf{1}$ from 5 (Fig. 3) in that the data for control (no cholesterol) was not measurably different from the experiment containing equimolar or a ten-fold molar excess of cholesterol.
It was also of interest to observe the dissociation of $\mathbf{5}$ (to $\mathbf{1}$ and $\beta$-CyD) and subsequent hydrolysis of $\mathbf{1}$ in plasma to form IUdR. Data were obtained at $1.2 \mathrm{mM}$ and $6.2 \mathrm{mM} \mathbf{5}$ in plasmaoctanol. Data for the $6.2 \mathrm{mM}$ experiment are shown in Figure 4. At $1.2 \mathrm{mM}$, approximately 60 $\%$ of 1 remained after $80 \mathrm{~min}$ ( $\sim 40 \%$ is hydrolyzed to IUdR), while at $6.2 \mathrm{mM}$, even after $5 \mathrm{~h}, 60 \%$ of the prodrug 1 still remained. Slopes of the regression lines for concentrations of $\mathbf{1}$ were $0.5338\left(\mathrm{R}^{2}=0.9972\right)$ and $-0.6143\left(\mathrm{R}^{2}=0.9756\right)$ at 1.2 and $6.2 \mathrm{mM}$, respectively. The apparent transfer of 1 from plasma into octanol is much slower (slope $-0.174, \mathrm{R}^{2}=0.8907 ; 1.2 \mathrm{mM}$ ), reflecting the hydrolysis of 1 as a competing reaction in plasma. In another experiment, when dissolved in plasma:DMSO $=19: 1$ at a lower concentration $(0.3$ $\mathrm{mM}$ ) to circumvent difficulties introduced by the low solubility of $\mathbf{1}$ in water, $90 \%$ of $\mathbf{1}$ was hydrolyzed in $30 \mathrm{~min}$, compared to $10 \%$ for $\mathbf{5}$.

\section{DISCUSSION}

The utilization of O'-adamantyl derivitization as a protective device in nucleoside synthesis is a fortyplus year old concept (19).

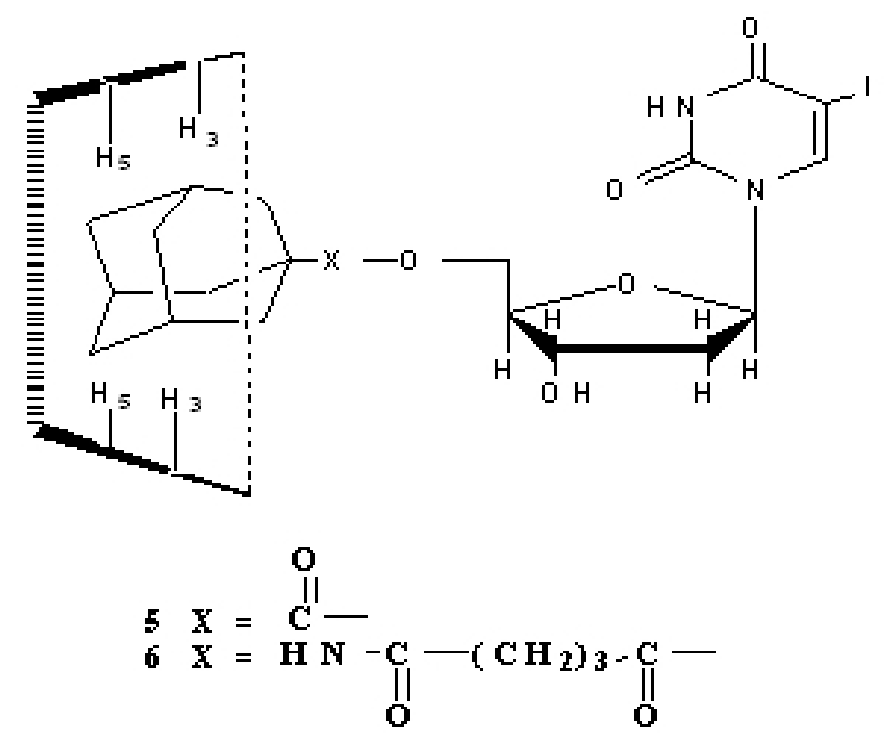

Scheme 2. CyD/IUdR-Prodrug complexes 5 and 6 , with schematic representation of $\beta$-CyD protons H-3 and H-5. Only two of seven sets of H-3 and H-5 protons are depicted. 


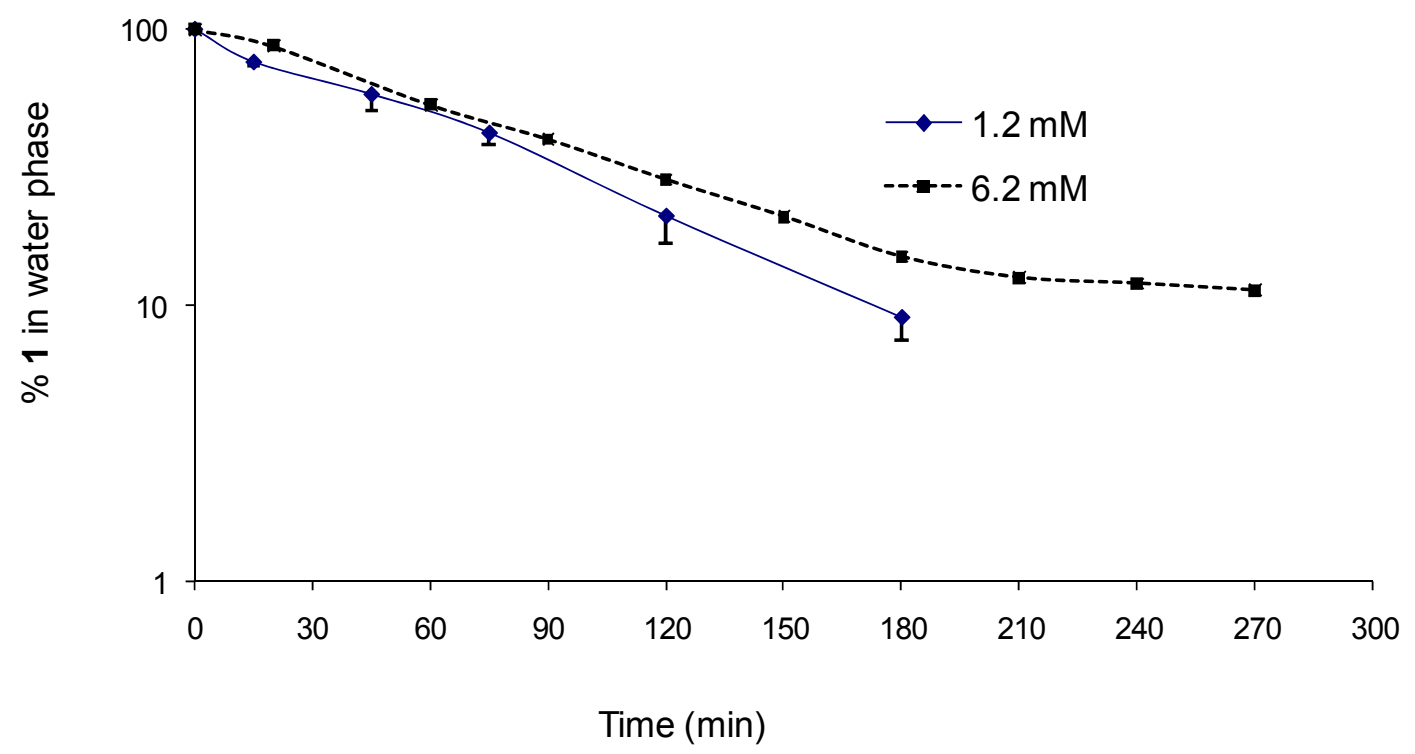

Figure 2. Dissociation of $5(1.2$ and $6.2 \mathrm{mM})$ in water. Each time interval represents the average of 3 determinations, and lower error bars (1.2 $\mathrm{mM}$ only) represent the standard deviation. Lines are smoothed point-to-point fit. Calculated data were derived using Excel (Microsoft).

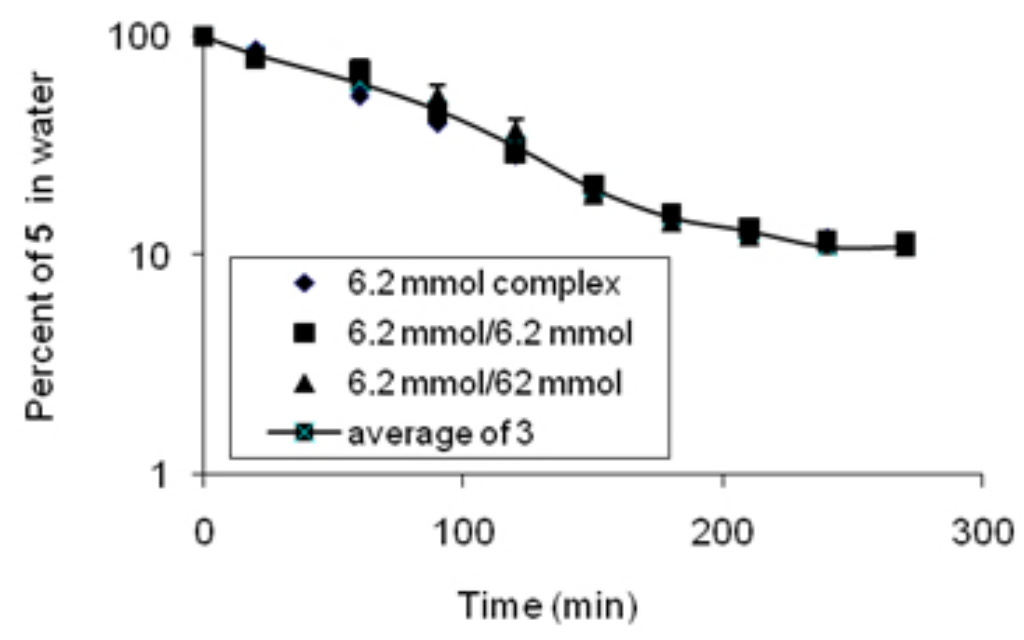

Figure 3. Displacement of 1 from 5 by cholesterol in aqueous solution. The line represents the point-to-point fit to average values for the three concentrations. Error bars (S.D.) are shown only where the scale permits. Calculated data were derived using Excel (Microsoft).

Early biochemical applications of these derivatives included their use as folate metabolism inhibitors (20) and as antiviral agents (21). Technical applications have included the use of microwaveassisted reaction to direct substitution to 5'-O- to avoid heterocyclic adamantylation $(22,23)$. The current syntheses of adamantanoyl-IUdR ester $\mathbf{1}$ and analogue 4 , based on 1-adamantanecarbonyl chloride and also an analogue with a 4-carbon spacer between IUdR and adamantanamine, 
proceeded smoothly. Formation of the 3',5'-di- $O$ adamantantoyl 2 was minimal, and although this compound was characterized, no further studies were undertaken with it. The ${ }^{1} \mathrm{H}$ NMR spectrum of 1 was in excellent agreement with the proposed structure, and only a single set of adamantane protons was observed, along with a corresponding downfield shift for the H-5' protons of IUdR to 4.48 and $4.25 \mathrm{ppm}$, respectively. The ${ }^{1} \mathrm{H}$ NMR data for 2 revealed two sets of adamantane signals, and in addition to the downfield shift for the H-5' protons, the $\mathrm{H}-3$ ' proton signal was shifted downfield to $5.18 \mathrm{ppm}$.

Adamantanylation has also been used to increase the lipophilicity of nucleosides and other drugs in attempts to increase their penetration of the blood-brain-barrier (24). Indeed both 1 and $\mathbf{4}$ were found to be poorly water soluble, whereas the resulting complexes 5 and $\mathbf{6}$, respectively, were much more water soluble. This complexation provided a solubility enhancement factor (25) of 300 relative to the solubility of 1 . The $A_{L}$ phase solubility diagram stoichiometry (Fig. 1) for 1 in aqueous solutions of $\beta$-CyD implies a linear increase in solubility with increasing $\beta-\mathrm{CyD}$ concentration, but with unchanged (26).

Evidence for inclusion complexation between $\mathbf{1}$ and $\beta$-CyD was provided by DSC, X-ray powder diffractometry and proton NMR. Thermograms for each of the test materials $(1, \beta-C y D$, their physical mixture and 5) were markedly different from each other. Characteristically, the mixture featured two endothermic peaks $\left(220{ }^{\circ} \mathrm{C}\right.$ and $\left.227^{\circ} \mathrm{C}\right)$ and an exothermic peak at $240{ }^{\circ} \mathrm{C}$, whereas 5 had an endothermic peak at $235^{\circ} \mathrm{C}$. Prodrug 1 showed one exothermic peak at $208{ }^{\circ} \mathrm{C} ; \mathbf{1}$ underwent decomposition at this temperature, as shown by the presence of numerous components upon post-DSC thin-layer chromatographic analysis.

$\mathrm{X}$-ray powder diffractometry has been used for the characterization of $\beta-C y D$ complexes in solid phase (27). The x-ray powder pattern of every crystalline form of a compound is unique, and indeed the diffractograms for the mixture and inclusion complex 5 differ. However, this technique has limited utility in the identification of noncrystalline (amorphous) materials since their patterns consist of one or more broad diffuse peaks as in the case of 5 .

${ }^{1} \mathrm{H}$ NMR provided strong evidence of the inclusion of the adamantly moiety into the $\beta-\mathrm{CyD}$ cavity, and of the host-guest ratio in the complex. The schematic representation of the complexes (Scheme 2) shows that cyclodextrin protons H-3 and $\mathrm{H}-5$ are only accessible from within the cavity, thus, proton NMR provides a means of probing the depth of inclusion of a guest molecule into the CyD cavity (28). Utilization of this approach to determine binding coefficients is beyond the scope of the present work, and will be published elsewhere.

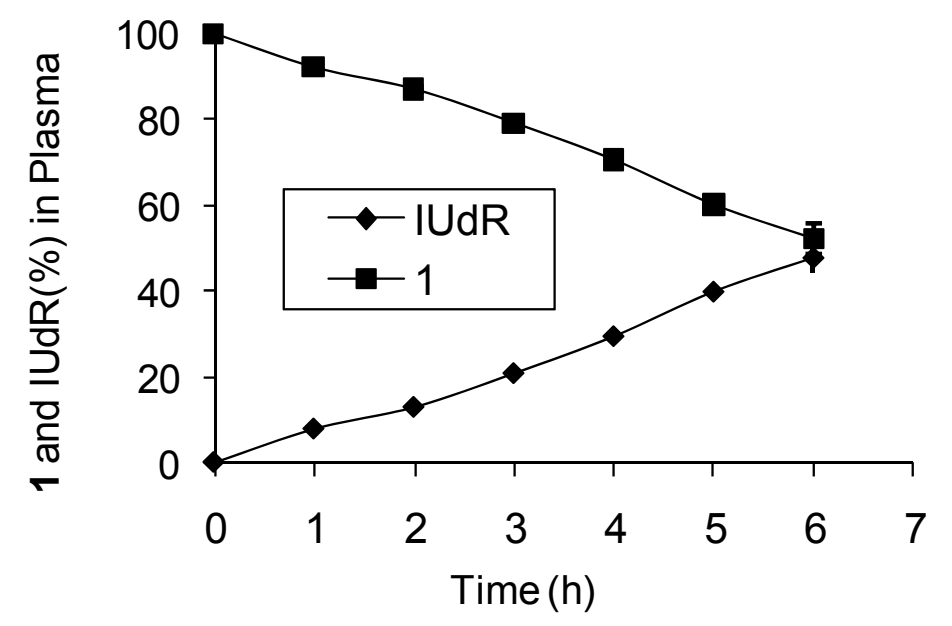

Figure 4. Dissociation of 5 (6.2 $\mathrm{mM}$ in plasma) to 1 , and hydrolysis of 1 to IUdR at $37^{\circ} \mathrm{C}$. Calculated data were derived using Excel (Microsoft). 
The $\beta$-CyD-adamantoyl-IUdR complex formulations $\mathbf{5}$ and $\mathbf{6}$ were designed to form high affinity inclusion complexes that would provide longer circulation residence times, as observed for other lipids (29). The transformation of complex 5 to the active form (IUdR) after administration must therefore proceed in two steps: first, 1 must dissociate from the host $\beta$-CyD; and second, 1 must be hydrolyzed to the active form (IUdR) by blood and cellular esterases. Data from the simple aqueous solubility and dissociation models support the hypotheses that the $\beta$-CyD-adamantoyl-IUdR binding in $\mathbf{5}$ is sufficient and that dissociation may be low enough to influence (i.e., prolong) circulation times of the adamantoyl-IUdR prodrug. Thus, dissociation of $\mathbf{5}$ in water was virtually independent of concentration over a $3 \mathrm{~h}$ period at these concentrations, but at longer intervals, the system appeared to reach equilibrium (i.e., plateau) at $6.2 \mathrm{mM}$ (Fig. 2). The stability constant for $\mathbf{5}$, calculated from the phase solubility diagram (Fig. 1) according to Higuchi and Connors (26) was 1.49 x $10^{5} \mathrm{M}^{-1}$. It has been reported that a constant of $1 \mathrm{x}$ $10^{5} \mathrm{M}^{-1}$ would limit dilution-related dissociation at 1:4200 dilution to about $33 \%(30)$, in reasonable agreement with the experimental estimates of about $10 \%$ for 5 , keeping in mind that the current experimental model provides sink conditions, removing the poorly water soluble $\mathbf{1}$, thereby shifting equilibrium away from $\mathbf{5}$.

To develop a more biologically representative system, dissociation of $\mathbf{5}$ from plasma was investigated. Fresh plasma contains not only esterases which will hydrolyze 1 to IUdR, and also lipoidal biochemicals such as cholesterol that are effective ligands for inclusion complex formation. The rate of enzymatic hydrolysis of the CyD inclusion complex 5 relative to hydrolysis of $\mathbf{1}$ to IUdR provided indirect evidence for protection of 1 through CyD inclusion complexation through gradual rather than immediate dissociation of the complex. This process proceeded at nearly identical rates over a five-fold concentration range. Because $\mathbf{1}$ is sparingly soluble in aqueous media, direct comparison between the hydrolysis of $\mathbf{1}$ and $\mathbf{5}$ in plasma was not possible, but in another experiment using a water:DMSO=19:1 solvent mixture similar results were obtained.
These in vitro data confirm that release and hydrolysis of the prodrug 1 from the CyD-prodrug complex $\mathbf{5}$ is slower than hydrolysis of $\mathbf{1}$ to IUdR, thereby offering the prospect of extended prodrug circulation times (longer plasma clearance $T_{1 / 2}$ ) for improved delivery of IUdR to target tissues.

It has been reported that cholesterol forms a complex with $\beta$-CyD in vivo with an association constant of $1.7 \times 10^{4} \mathrm{M}^{-1}$ (31). In the presence of cholesterol, many drug/ $\beta$-CyD complexes quickly dissociate in vivo because cholesterol effectively competes with $\beta$-CyD for drug binding. This is highly undesirable, as the cholesterol/ $\beta-C y D$ complex has been found to crystallize in the kidney and cause kidney damage (32). In fact, this is the major drawback of using CyDs for parenteral drug delivery. In this study, we chose to investigate the stability of the complex at two different the cholesterol concentrations: $6.2 \mathrm{mM}$ and $62 \mathrm{mM}$ (in humans the total serum cholesterol concentrations is 5.2-6.2 $\mathrm{mM}$ ) while the inclusion complex concentration was maintained at $6.2 \mathrm{mM}$. The experiment data (Fig. 3) show that even at a cholesterol concentration 10 times higher than the complex, dissociation is not changed, that is, cholesterol competed poorly for binding to $\beta-\mathrm{CyD}$. This effect would be expected based on the apparent ten-fold higher binding constant between $\beta-\mathrm{CyD}$ and 1 than between cholesterol and $\beta-\mathrm{CyD}$, but the magnitude of the effect is greater than expected. The experimental model used in this challenge study has not been validated. The basic premise is that effective mixing of the two liquid phases will promote sufficient diffusion of cholesterol into the aqueous phase for effective challenge to occur. This is clearly an oversimplification of the partition process (33) and may not adequately counter the impact of the high octanol-water partition coefficient $\left(\log _{10} \mathrm{P} \sim 8.7\right)$ of cholesterol (34). Clearly additional studies are required to establish the validity of this experimental approach and the stability of these CyD complexes in the presence of cholesterol.

\section{EXPERIMENTAL SECTION}

General. NMR spectra were recorded on a Bruker AM 300 spectrometer $\left({ }^{1} \mathrm{H}: 300 \mathrm{MHz} ;{ }^{13} \mathrm{C}: 75 \mathrm{MHz}\right)$ or Varian Unity 500 spectrometer $\left({ }^{1} \mathrm{H}: 500 \mathrm{MHz}\right)$ in 
$\mathrm{CDCl}_{3}$ or $\mathrm{D}_{2} \mathrm{O}$ solution unless otherwise stated. Chemical shifts in $\mathrm{CDCl}_{3}$ solutions are reported in parts per million downfield from TMS, or in the case of $\mathrm{D}_{2} \mathrm{O}$ solutions, using HOD set at $\delta 4.82(25$ ${ }^{\circ} \mathrm{C}$ ) unless otherwise specified. ${ }^{13} \mathrm{C}$ NMR spectral assignments were aided by the J-MOD technique (35). Electrospray (ES) mass spectra were obtained with a Fisons VG Trio-2000 instrument in the negative ion mode. Reactions were monitored by thin-layer chromatography (TLC) on Kieselgel 60 $\mathrm{F}_{254}$ (Merck) and visualization was accomplished by charring with $5 \%$ methanolic sulfuric acid. Column chromatography was performed using Merck 9385 silica gel $(40-63 \mu \mathrm{m})$.

$\beta$-Cyclodextrin, 1-adamantanamine hydrochloride, 1-adamantanecarboxylic acid, IUdR and 1-octanol (99.99\% spectroscopic grade) were purchased from Sigma Aldrich Canada Ltd. Cyclodextrin was dried in vacuo over $\mathrm{P}_{2} \mathrm{O}_{5}$ at $60{ }^{\circ} \mathrm{C}$ prior to use. Chloroform was distilled from $\mathrm{P}_{2} \mathrm{O}_{5}$ and pyridine was distilled from $\mathrm{CaH}_{2}$ and stored over molecular sieves $3 \AA$. For measurement of the rate of hydrolysis in plasma, centrifugation was performed in Eppendorf microcentrifuge tubes using an Eppendorf 5412 microcentrifuge. Samples were filtered through a Millex ${ }^{\circledR}$ low protein binding $0.22 \mu \mathrm{m}$ filter (Millipore) was used for filtering plasma samples prior to analysis.

HPLC analysis was performed using a Waters model U6K injector equipped with dual Waters 501 solvent delivery pumps. Chromatographic separation of the IUdR prodrug from IUdR was performed on a reverse-phase column (phenyl radial-pak cartridge; $10 \mu \mathrm{m}$ particle size, $8 \mathrm{~mm}$ id $\times 100 \mathrm{~mm}$ length) equipped with a guard column ( $\mu$ Bondapak $^{\mathrm{TM}}$ phenyl Guard-pak ${ }^{\mathrm{TM}}$ ) using 4:1 methanol:water as eluant (flow rate of 1 $\mathrm{mL} / \mathrm{min}$ ). Detection was accomplished with a Waters 486 tunable absorbance detector set at 288 nm.

\section{5'-O-(1-Adamantoyl)-5-iodo-2'-}

deoxyuridine 1 and 3',5'-di-O-(1-adamantoyl)-5iodo-2'-deoxyuridine 2. A solution of 5-iodo-2'deoxyuridine (400 mg, $1.13 \mathrm{mmol}$ ) in dry pyridine $(7 \mathrm{~mL})$ was cooled to $0-5{ }^{\circ} \mathrm{C}$ under argon. To this mixture was added drop-wise, a solution of freshly prepared 1-adamantanecarbonyl chloride $(300 \mathrm{mg}$, $1.5 \mathrm{mmol})$ in dry chloroform $(3 \mathrm{~mL})$. The reaction was stirred at this temperature for $30 \mathrm{~min}$, then allowed to warm to room temperature and stirred overnight. Excess methanol $(0.1 \mathrm{~mL})$ was added to the reaction mixture and then mixture was concentrated. The residue was dissolved in chloroform and successively washed with saturated aqueous sodium hydrogen carbonate, water, saturated sodium chloride, and then dried $\left(\mathrm{Na}_{2} \mathrm{SO}_{4}\right)$, filtered and concentrated. Column chromatography over silica gel using 12:12:1 hexane:ethyl acetate:ethanol gave first the di-adamantanyl derivative $261 \mathrm{mg}$ (8\%) followed by $498 \mathrm{mg}(69$ $\%$ ) of the desired IUdR derivative 1. Compound 1: $\mathrm{R}_{\mathrm{f}}=0.18$ (12:12:1 hexane:ethyl acetate:ethanol); mp 124-125 ${ }^{\circ} \mathrm{C}$; UV: (1-octanol) $\lambda \max 207,285$ $\mathrm{nm} ;{ }^{1} \mathrm{H}$ NMR $\left(500 \mathrm{MHz}, \mathrm{CDCl}_{3}\right) \delta 9.05(\mathrm{~s}, 1 \mathrm{H}$, $\mathrm{NH}), 7.91(\mathrm{~s}, 1 \mathrm{H}, \mathrm{H}-6), 6.23\left(\mathrm{t}, 1 \mathrm{H}, J_{t}=6.6 \mathrm{~Hz}, \mathrm{H}-\right.$ $\left.1^{\prime}\right), 4.48\left(\mathrm{dd}, 1 \mathrm{H}, J_{5^{\prime} a, 5^{\prime} b}=12.7 \mathrm{~Hz}, J_{5^{\prime} a, 4^{\prime}}=1.9 \mathrm{~Hz}\right.$, H-5'a), 4.37 (m, 1H, H-3'), 4.25 (dd, $1 \mathrm{H}, J_{5^{\prime} b, 5^{\prime} a}=$ $12.7 \mathrm{~Hz}, J_{5^{\prime} b 4^{\prime}}=1.9 \mathrm{~Hz}, \mathrm{H}-5^{\prime}$ b), 4.23 (s, 1H, H-4'), $2.53\left(\mathrm{ddd}, 1 \mathrm{H}, J_{2^{\prime} a, 2^{\prime} b}=13.4 \mathrm{~Hz}, J_{2^{\prime} a, 1^{\prime}}=6.6 \mathrm{~Hz}\right.$, $\left.J_{2^{\prime} a, 3^{\prime}}=2.8 \mathrm{~Hz}, \mathrm{H}-2{ }^{\prime} \mathrm{a}\right), 2.06$ (m, 1H, H-2'b), 2.06 $(\mathrm{m}, 3 \mathrm{H}$ adamantane $\gamma$-protons), $1.93(\mathrm{~m}, 6 \mathrm{H}$, adamantane $\alpha$-protons $), 1.74(\mathrm{~m}, 6 \mathrm{H}$, adamantane $\beta$-protons $){ }^{13} \mathrm{C} \mathrm{NMR}\left(\mathrm{CDCl}_{3}\right) \delta 175.0,157.4,147.3$, 141.3, 83.2, 82.5, 68.9, 66.2, 60.9, 38.6, 38.4, 36.5, 33.7, 25.2; Anal. Cal. for $\mathrm{C}_{20} \mathrm{H}_{25} \mathrm{IN}_{2} \mathrm{O}_{6} \cdot 1 \mathrm{H}_{2} \mathrm{O}$ : C 44.94, H 5.05, N 5.24; Found C 44.53, H 4.65, N 5.42. Data for compound 2: $\mathrm{R}_{\mathrm{f}}=0.36(12: 12: 1$ hexane/ethyl acetate/ethanol); ${ }^{1} \mathrm{H}$ NMR (300 MHz, $\left.\mathrm{CDCl}_{3}\right) \delta 8.39$ (s, 1H, NH), 7.89 (s, 1H, H-6), 6.23 $\left(\mathrm{dd}, 1 \mathrm{H}, J_{1^{\prime}, 2^{\prime} b}=8.9 \mathrm{~Hz}, J_{l^{\prime}, 2^{\prime} a}=5.1 \mathrm{~Hz}, \mathrm{H}-1\right.$ '), 5.18 $\left(\mathrm{d}, 1 \mathrm{H}, J_{d}=6.1 \mathrm{~Hz}, \mathrm{H}-3^{\prime}\right), 4.45\left(\mathrm{dd}, 1 \mathrm{H}, J_{5^{\prime} a, 5^{\prime} b}=\right.$ $12.5 \mathrm{~Hz}, J_{5^{\prime} a, 4^{\prime}}=3.4 \mathrm{~Hz}, \mathrm{H}-5$ ' $\mathrm{a}$ ), 4.29 (dd, $1 \mathrm{H}, J_{5^{\prime} b, 5^{\prime} a}$ $\left.=12.5 \mathrm{~Hz}, J_{5^{\prime} b, 4^{\prime}}=2.4, \mathrm{H}-5^{\prime} \mathrm{b}\right), 4.23$ (m, $\left.1 \mathrm{H}, \mathrm{H}-4^{\prime}\right)$, $2.54\left(\mathrm{dd}, 1 \mathrm{H}, J_{2^{\prime} a, 2^{\prime} b}=14.0 \mathrm{~Hz}, J_{2^{\prime} a, 1^{\prime}}=5.1 \mathrm{~Hz}, \mathrm{H}-\right.$ 2'a), 2.1 (m, 1H, H-2'b, obscured by adamantane $\beta$ protons), 2.04 ( $\mathrm{m}, 6 \mathrm{H}$, adamantane $\beta$-protons), 1.92 (m, 6H, adamantane $\alpha$-protons), 1.87 (m, 6H, adamantane $\alpha$-protons ), $1.72(\mathrm{~m}, 12 \mathrm{H}$, adamantane $\beta$-protons).

4-(1-Adamantylcarbamoyl)butanoic acid 3. Adamantanamine hydrochloride $(188 \mathrm{mg}, 1.0$ mmol) was dissolved in 1:1 anhydrous pyridine:chloroform, and glutaric anhydride (180 $\mathrm{mg}, 1.5 \mathrm{mmol}$ ) was added to the reaction mixture. The reaction mixture was stirred at $75{ }^{\circ} \mathrm{C}$ under argon for $18 \mathrm{~h}$. The solvent was evaporated in vacuo and the residue redissolved and evaporated sequentially with chloroform ( $15 \mathrm{~mL}$ x 3$)$, methanol 
$(15 \mathrm{~mL})$ and, lastly, chloroform $(15 \mathrm{~mL} \times 2)$. The residue was then triturated with chloroform and left overnight at room temperature. The precipitate was collected by filtration, washed with cold chloroform and dried in vacuo to afford $215 \mathrm{mg}(81 \%)$ of 3 as a white solid: mp $225-227{ }^{\circ} \mathrm{C} ;{ }^{1} \mathrm{H}$ NMR $(300 \mathrm{MHz}$, DMSO- $\left.d_{6}\right) \delta 7.24(\mathrm{~s}, 1 \mathrm{H}, \mathrm{NH}), 3.34($ br s, $1 \mathrm{H}$, $\mathrm{CO}_{2} \mathrm{H}$ ), 2.17 (t, $\left.2 \mathrm{H}, J_{t}=7.3 \mathrm{~Hz}, \mathrm{CH}_{2} \mathrm{CO}_{2} \mathrm{H}\right) 2.02$ (t, $\left.2 \mathrm{H}, J_{t}=7.3 \mathrm{~Hz}, \mathrm{CH}_{2} \mathrm{CON}\right), 2.0($ br $\mathrm{s}, 3 \mathrm{H}$, adamantane $\beta$-protons), 1.89 (br s, $6 \mathrm{H}$, adamantane $\alpha$-protons), 1.65 (quintet, $2 \mathrm{H}, J=7.3 \mathrm{~Hz}$, $\left.\mathrm{CH}_{2} \underline{\mathrm{C}}_{2} \mathrm{CH}_{2}\right) 1.60$ (br s, $6 \mathrm{H}$, adamantane $\gamma$-protons) ${ }^{13} \mathrm{C}$ NMR (DMSO- $\left.d_{6}\right) \delta 174.0,170.8,50.4,50.0$, 36.0, 35.2, 32.9, 29.0, 20.8; ES MS (negative ion) calc. for $\mathrm{C}_{15} \mathrm{H}_{22} \mathrm{NO}_{3}[\mathrm{M}-\mathrm{H}]-$ : 264.3; found: 264.6.

5'-O-(4-(1-Adamantylcarbamoyl)butoyl)-5iodo-2'-deoxyuridine 4. A mixture of $3(121 \mathrm{mg}$, $0.46 \mathrm{mmol}$ ), 5-iodo-2'-deoxyuridine (82 $\mathrm{mg}, 0.23$ $\mathrm{mmol})$ and dicyclo-hexylcarbodiimide (100 $\mathrm{mg}$, $0.48 \mathrm{mmol})$ in dry pyridine $(3 \mathrm{~mL})$ was stirred at 70 ${ }^{\circ} \mathrm{C}$ under argon, overnight. The TLC profile (9:1 chloroform:methanol) of the reaction mixture revealed that one major and two relatively minor components were present as well as a significant amount of starting material. The solvent was removed, the mixture dissolved in chloroform and the organic solution was washed sequentially with saturated aqueous sodium hydrogen carbonate and water, dried $\left(\mathrm{Na}_{2} \mathrm{SO}_{4}\right)$, filtered, and concentrated. Purification of the residue by column chromatography over silica using 97:3 chloroform:methanol as eluent gave $59 \mathrm{mg}$ (42\%) of 4 as a white solid: $\mathrm{R}_{\mathrm{f}}=0.42 \quad(9: 1$ chloroform/methanol); mp $105{ }^{\circ} \mathrm{C}$; ${ }^{1} \mathrm{H}$ NMR (500 $\left.\mathrm{MHz}^{\mathrm{CDCl}} \mathrm{CD}_{3}\right) \delta .22(\mathrm{~s}, 1 \mathrm{H}, \mathrm{NH}), 8.04$ (s, 1H, H-6), $6.16\left(\mathrm{dd}, 1 \mathrm{H}, J_{l^{\prime}, 2^{\prime} a}=6.3 \mathrm{~Hz}, J_{l^{\prime}, 2^{\prime} b}=4.4 \mathrm{~Hz}, \mathrm{H}-1^{\prime}\right)$, $5.2($ br s, $1 \mathrm{H}, \mathrm{NH}), 4.55$ (q, $1 \mathrm{H}, J_{t}=6.5 \mathrm{~Hz}, \mathrm{H}-3$ '), $4.52\left(\mathrm{dd}, 1 \mathrm{H}, J_{5^{\prime} a, 5^{\prime} b}=12.5 \mathrm{~Hz}, J_{5^{\prime} a, 4^{\prime}}=2.5 \mathrm{~Hz}, \mathrm{H}-\right.$ $\left.5^{\prime} \mathrm{a}\right), 4.22\left(\mathrm{dd}, 1 \mathrm{H}, J_{5^{\prime} b, 5^{\prime} a}=12.5 \mathrm{~Hz}, J_{5^{\prime} b, 4^{\prime}}=3.0, \mathrm{H}-\right.$ $5^{\prime}$ b), 4.09 (dt, $1 \mathrm{H}, J_{4^{\prime \prime}, 3^{\prime}}=6.0 \mathrm{~Hz}, J_{4^{\prime}, 5^{\prime} a, b}=3.0 \mathrm{~Hz}$, H-4'), $2.65\left(\mathrm{dt}, 1 \mathrm{H}, J_{d}=15.0, \mathrm{~Hz}, J_{t}=6.0 \mathrm{~Hz}\right.$, $\left.\mathrm{CHCO}_{2}\right) 2.49\left(\mathrm{dd}, 1 \mathrm{H}, J_{2^{\prime} a, 2^{\prime} b}=13.5 \mathrm{~Hz}, J_{2^{\prime} a, 1^{\prime}}=6.3\right.$ $\mathrm{Hz}, \mathrm{H}-2$ 'a), 2.42 (ddd, $1 \mathrm{H}, J_{d}=15.0 \mathrm{~Hz}, J_{d}=8.0$ $\left.\mathrm{Hz}, J_{d}=6.0 \mathrm{~Hz}, \mathrm{CHCO}_{2}\right) 2.25(\mathrm{~m}, 2 \mathrm{H}, \mathrm{CHCON}$ and $\mathrm{H}-2$ 'b), (m, 1H, CHCON), 2.06 (br s, 3H, adamantane $\beta$-protons), 1.95 (m, 8H, $\mathrm{CH}_{2} \mathrm{CH}_{2} \mathrm{CH}_{2}$ and adamantane $\alpha$-protons), 1.66 (br s, 6H, adamantane $\quad \gamma$-protons $) \quad{ }^{13} \mathrm{C} \quad \mathrm{NMR} \quad(1: 1$ $\left.\mathrm{CD}_{3} \mathrm{OD} / \mathrm{CDCl}_{3}\right)$ 172.8, 172.2, $160.5,149.9,144.2$,
$85.6,84.3,69.9,68.2,63.2,52.2,41.2,40.4,36.1$, 35.7, 33.2, 29.4, 21.0; Anal. Calc. for $\mathrm{C}_{24} \mathrm{H}_{32} \mathrm{IN}_{3} \mathrm{O}_{7} .1 / 4 \mathrm{H}_{2} \mathrm{O}$ : Calc. C 47.56, H 5.36, N 6.94; Found C 47.09, H 5.24, N 7.24\%.

$\beta$-cyclodextrin complex 5 . A 1:1 solution of $5 \mu \mathrm{mol}$ each of $\beta$-cyclodextrin and IUdR prodrug $1(\log \mathrm{P}=1.91)$ in $\mathrm{D}_{2} \mathrm{O}(600 \mu \mathrm{L})$ was stirred vigorously under argon at $50{ }^{\circ} \mathrm{C}$ for $30 \mathrm{~min}$, then cooled to room temperature and filtered into an NMR tube. The ${ }^{1} \mathrm{H}$ NMR spectrum $(500 \mathrm{MHz}$, $\mathrm{D}_{2} \mathrm{O}$ ) revealed (integration) that a $1: 1$ mixture was present in solution; $\delta 8.16(\mathrm{~s}, 1 \mathrm{H}, \mathrm{H}-6 \mathrm{IUdR}), 6.26$ (t, $1 \mathrm{H}, J_{t}=6.4 \mathrm{~Hz}, \mathrm{H}-1$ ' IUdR), 5.14 (d, 7H, $J_{d}=3.4$ $\mathrm{Hz}, \mathrm{H}-1 \mathrm{CyD}), 4.58$ (m, 1H, H-3' IUdR), 4.47(m, 2H, H-5'a, H-5'b IUdR), 4.28 (br m, 1H, H-4' IUdR), 3.95 (t, 7H, $\left.J_{t}=9.8 \mathrm{~Hz}, \mathrm{H}-3 \mathrm{CyD}\right), 3.93-$ 3.88 (m, 17H, H-4', H-5'a, H-5'b IUdR, H-6a, H6b CyD), 3.85 (br d, 7H, $J_{d}=9.8 \mathrm{~Hz}, \mathrm{H}-5 \mathrm{CyD}$ ), $3.73\left(\mathrm{dd}, 7 \mathrm{H}, J_{2,3}=9.8 \mathrm{~Hz}, J_{2,1}=3.4 \mathrm{~Hz}, \mathrm{H}-2 \mathrm{CyD}\right)$, 3.67 (t, 7H, $\left.J_{t}=9.8 \mathrm{~Hz}, \mathrm{H}-4 \mathrm{CyD}\right), 2.64$ (br m, 1H, H-2'a IUdR), 2.40 (br m, 1H, H-2'b IUdR), 2.25 (br $\mathrm{s}, 3 \mathrm{H}$, adamantane $\beta$-protons), 2.00 (br s, $6 \mathrm{H}$, adamantane $\alpha$-protons), $1.91\left(\mathrm{~d}, 3 \mathrm{H}, J_{d}=12.0 \mathrm{~Hz}\right.$ adamantane $\gamma_{\mathrm{a}}$-protons), $1.82\left(\mathrm{~d}, 3 \mathrm{H}, J_{d}=12.0 \mathrm{~Hz}\right.$ adamantane $\gamma_{\mathrm{b}}$-protons).

$\beta$-cyclodextrin complex 6. A 1:1 solution of $5 \mu \mathrm{mol}$ each of $\beta$-cyclodextrin and IUdR prodrug 4 in $\mathrm{D}_{2} \mathrm{O}(600 \mu \mathrm{L})$ was stirred under argon at $50{ }^{\circ} \mathrm{C}$ for $30 \mathrm{~min}$ as described for $\mathbf{5}$, then cooled to room temperature and filtered into an NMR tube. The ${ }^{1} \mathrm{H}$ NMR spectrum $\left(500 \mathrm{MHz}, \mathrm{D}_{2} \mathrm{O}\right)$ revealed that a $1: 1$ mixture was present in solution; $\delta 8.22(\mathrm{~s}, 1 \mathrm{H}, \mathrm{H}-6$ IUdR), 6.31 (t, 1H, $J_{t}=6.4 \mathrm{~Hz}, \mathrm{H}-1$ ' IUdR), 5.18 (br s, 7H, H-1 CyD), 4.58 (m, 1H, H-3' IUdR), 4.50 (dd, $1 \mathrm{H}, J_{5^{\prime} a 5^{\prime} b}=12.2 \mathrm{~Hz}, J_{5^{\prime} a, 4^{\prime}}<1.0 \mathrm{~Hz}, \mathrm{H}-5^{\prime} \mathrm{a}$ ), $4.45\left(\mathrm{dd}, 1 \mathrm{H}, J_{5^{\prime} b, 5^{\prime} a}=12.2 \mathrm{~Hz}, J_{5 b a, 4^{\prime}}<1.0 \mathrm{~Hz}, \mathrm{H}-\right.$ 5'b), 4.34 (br s, 1H, H-4'), 3.96 (t, 7H, $J_{t}=9.8 \mathrm{~Hz}$, H-3 CyD), 3.94 (m, 14H, H-6a, H-6b CyD), 3.85 (br d, 7H, $J_{d}=9.3 \mathrm{~Hz}, \mathrm{H}-5 \mathrm{CyD}$ ), 3.73 (br dd, 7H, $J_{2,3}=9.8 \mathrm{~Hz}, \mathrm{H}-2 \mathrm{CyD}$ ), $3.64\left(\mathrm{t}, 7 \mathrm{H}, J_{t}=9.8 \mathrm{~Hz}, \mathrm{H}-\right.$ $4 \mathrm{CyD}$ ), 2.63-2.54 (br $\mathrm{m}, 3 \mathrm{H}, \mathrm{CH}_{2}$ and $\mathrm{H}-2$ 'a IUdR), 2.40 (br m, 1H, H-2'b IUdR), 2.25 (br s, 3H, adamantane $\beta$-protons), 2.00 (br s, $6 \mathrm{H}$, adamantane $\alpha$-protons), $1.91\left(\mathrm{~d}, 3 \mathrm{H}, J_{d}=12.0 \mathrm{~Hz}\right.$ adamantane $\gamma_{\mathrm{a}}$-protons), $1.82\left(\mathrm{~d}, 3 \mathrm{H}, J_{d}=12.0 \mathrm{~Hz}\right.$ adamantane $\gamma_{\mathrm{b}}$-protons).

Differential scanning calorimetry. Samples ( $2 \mathrm{mg}$ each) of free prodrug $1, \beta-\mathrm{CyD}$, the physical 
mixture of $\mathbf{1}$ and $\beta-\mathrm{CyD}$ and the inclusion complex 5 were loaded into aluminum pans and measured using a sealed aluminum pan as the reference. The instrument was calibrated with indium $\left(156^{\circ} \mathrm{C}\right)$. Thermograms were obtained at a heating rate of 10 ${ }^{\circ} \mathrm{C} / \mathrm{min}$ from $40{ }^{\circ} \mathrm{C}-180{ }^{\circ} \mathrm{C}$ and $5^{\circ} \mathrm{C} / \mathrm{min}$ from 180 ${ }^{\circ} \mathrm{C}-260{ }^{\circ} \mathrm{C}$. A nitrogen purge was maintained throughout each run.

$X$-ray diffractometry. Powder samples of prodrug $1, \beta-\mathrm{CyD}$, the physical mixture of the prodrug a 1 and $\beta-\mathrm{CyD}$, and the inclusion complex 5 were pressed onto a sample slide, and then covered with double-sided cellophane tape. An automated X-ray diffractometer equipped with a $2 \theta$ compensating slit, a nickel filter and Cobalt tube $(40 \mathrm{kV}, 30 \mathrm{~mA})$. Co $(\lambda \alpha=1.7962 \mathrm{~A} 0)$ was to use to obtain the diffraction patterns of the samples. The patterns were recorded from $2{ }^{\circ} \mathrm{C}-90{ }^{\circ} \mathrm{C}(2 \theta) /$ $\min$.

Partition coefficients $(\log P)$. The $\log P$ of 1 was determined using standard 1-octanol/ water and 1-octanol/phosphate-buffer solution $(0.02 \mathrm{M}$, $\mathrm{pH}=7.4)$ systems. Mechanical shaking was used to achieve equilibration, and UV spectroscopy was used for the quantitation of the analyte in the 1octanol phase. A standard solution of the prodrug was prepared in water-saturated 1-octanol. The standard sample was analyzed by UV spectrophotometry at $282 \mathrm{~nm}$ to prepare a standard curve of UV absorbance $v s$ concentration of the standard solution. Compound $1(0.5 \mathrm{mg} / \mathrm{mL})$ was partitioned between equal volumes $(2 \mathrm{~mL})$ of presaturated 1-octanol-water and 1octanol:phosphate buffer, respectively. The solutions were gently shaken for $24 \mathrm{~h}$ at room temperature. The two phases were then separated and the concentration of compound $\mathbf{1}$ in the 1octanol phase was determined by UV spectrophotometry, before and after partitioning. The partition coefficient $(\mathrm{P})$ was calculated as the molar ratio of the concentration in the 1-octanol to the concentration in the water or phosphate buffer phase, respectively, $\left(\mathrm{P}=\mathrm{C}_{n \text {-octanol }} / \mathrm{C}_{\text {water or buffer }}\right)$.

The $\log \mathrm{P}$ for $\mathbf{1}$ was also calculated by energy optimization of its chemical structure using Alchemy 32; Version 2 (1997), Tripos Inc., Louis, MD (U.S.A), then using subsequent analysis with SciQSAR, version 3.0 (1995-1998 Scivision, Inc.) to provide the calculated $\log P$ values.
Solubility of 1 in water and in aqueous $\beta-C y D$ solution. Excess prodrug 1 was added to water and an aqueous solution of $\beta$-CyD $(1.5 \mathrm{~mL})$ in Eppendorf centrifuge tubes, respectively. After 10 min of water bath sonication, the samples were placed in a shaking water bath at $25{ }^{\circ} \mathrm{C}$ and mixing was continued overnight. The samples were analyzed by HPLC with uv detection at $282 \mathrm{~nm}$. HPLC analyses were performed using a Waters reverse phase Phenyl Radial-Pak cartridge $(10 \mu \mathrm{m}$ particle size, $8 \mathrm{~mm}$ id x $10 \mathrm{~cm}$ length) using $4: 1 \mathrm{v} / \mathrm{v}$ methanol-water as solvent with a flow rate of 1 $\mathrm{mL} / \mathrm{min}$. The retention time of 1 was $4.4 \mathrm{~min}$.

Dissociation of the $1 / \beta-C y D$ inclusion complex 5 in water. Two concentrations $(1.2 \mathrm{mM}$ and $6.2 \mathrm{mM}$ in water) of the 1:1 molar ratio inclusion complex $\mathbf{5}$ were investigated. The inclusion complex $\mathbf{5}$ in water was transferred to a $1.5 \mathrm{~mL}$ vial containing 1 -octanol $(0.5 \mathrm{~mL})$ and placed into shaking water bath kept at $37{ }^{\circ} \mathrm{C}$. Aliquots of the octanol layer were taken at 0,15 , $45,75,120,180,240 \mathrm{~min}$. The aliquots $(50 \mu \mathrm{L})$ were analyzed by HPLC to determine the amount of free 1.

Stability of the prodrug $1 / \beta-C y D$ inclusion complex 5 to cholesterol challenge. The 1:1 molar ratio inclusion complex 5 in water $(1 \mathrm{~mL} ; 10.2$ $\mathrm{mg} / \mathrm{mL}, 6.2 \mathrm{mM})$ was added to 1 -octanol $(1 \mathrm{~mL})$, to 1-octanol $(1 \mathrm{~mL})$ containing $2.4 \mathrm{mg}(6.2 \mathrm{mmol})$ cholesterol) and to 1 -octanol $(1 \mathrm{~mL})$ containing 24 $\mathrm{mg}(62 \mathrm{mmol})$ cholesterol, respectively. These mixtures were placed into a shaking water bath at $37^{\circ} \mathrm{C}$. Aliquots were taken for HPLC analysis at 0 , 20, 60, 90, 120, 150, 180, 210, 240, $270 \mathrm{~min}$.

Hydrolysis of the $1 / \beta-C y D$ complex 5 to $I U d R$ in plasma. A solution of $\mathbf{5}$ in plasma (1.2 $\mathrm{mM}$ ) was transferred to a $1.5 \mathrm{~mL}$ vial containing 1octanol $(0.5 \mathrm{~mL})$ and placed into shaking water bath kept at $37{ }^{\circ} \mathrm{C}$. Aliquots $(50 \mu \mathrm{L})$ of the supernatant were taken at 0, 15, 45, 75, 120, 180, $240 \mathrm{~min}$. Each aliquot was quenched with methanol $(400 \mu \mathrm{L})$, and the resultant solution was centrifuged at $2500 \mathrm{~g}$ (2 $\min )$. The supernatant was then carefully removed, filtered through a $0.22 \mu \mathrm{m}$ MILLEX GV filter, and analyzed for the $\mathbf{1}$ and IUdR by HPLC. 


\section{ACKNOWLEDGEMENTS:}

We wish to thank Dr. Hassan Monzavi for generating NMR spectral data. This project was funded in part through grants from the Alberta Cancer Board (RI-14) and the Canadian Institutes for Health Research (13480).

\section{REFERENCES}

[1]. McGinn, C.J., Shewach, D.S., Lawrence, T.S. Radiosensitizing nucleosides. J Natl Cancer Inst, 88: 1193-1203, 1996.

[2]. Epstein, A.H., Lebovics, R.S., Van Waes, C., Smith, J., Okunieff, P., Cook, J.A. Intravenous delivery of 5'-iododeoxyuridine during hyperfractionated radiotherapy for locally advanced head and neck cancers: results of a pilot study. Laryngoscope, 108: 1090-1094, 1998.

[3]. Philip, P.A., Bagshawe, K.D., Searle, F., Green, A.J., R.H.J. Begent, Newlands, E.S., Rustin, G.J.S., Adam, T. In vivo uptake of ${ }^{131}$ I-5-iodo-2'deoxyuridine by malignant tumors in man. $\mathrm{Br} \mathrm{J}$ Cancer, 63: 134-135, 1991.

[4]. Chiou, R.K., Dalrymple, G.V., BaranowskaKortylewicz, Holdeman, K.P., Schneiderman, M.H., Harrison, K.A., Taylor, R.J. Tumor localization and systemic absorption of intravesical instillation of radio-iodinated iododeoxyuridine in patients with bladder cancer. J Urol, 162; 58-62, 1999.

[5]. Kassis, A.I. ${ }^{5-}{ }^{123} \mathrm{I} /{ }^{125} \mathrm{I}$-Iodo-2'-deoxyuridine for cancer diagnosis and therapy. J Nucl Med Allied Sci, 34: 299-303, 1990.

[6]. Mariani, G., Cei, A., Collecchi, P., BaranowskaKortylewicz, J., Van den Abbeele, A.D., Di Luca, L., Di Stefano, R., Viacava, P., Ferdeghini, E.M., Di Sacco, S., Salvadori, P.A., Bevilacqua, G., Adelstein, S.J., Mosca, F., Kassis, A.I. Tumor targeting in vivo and metabolic fate of 5-[iodine125]iodo-2'-deoxyuridine following intratumoral injection in patients with colorectal cancer. J Nucl Med, 34: 1175-1183, 1993.

[7]. Kassis, A.I., Wen, P.Y., Van den Abbeele, A.D., Baranowska-Kortylewicz, J., Makrigiorgos, G.M., Metz, K.R., Matalka, K.Z., Cook, C.U., Sahu, S.K., Black, P.M., Adelstein, S.J. 5$\left[{ }^{125}\right.$ I] Iodo-2'-deoxyuridine in the radiotherapy of brain tumors in rats. J Nucl Med, 39: 1148-1154, 1998.

[8]. Foulon, C.F., Zhang, Y.Z., Adelstein, S.J., Kassis, A.I. Instantaneous preparation of radiolabeled 5iodo-2'-deoxyuridine. Appl Radiat Isot, 46: 10391046, 1995.
[9]. Mariani, G., Collecchi, P., Giuliani, L., Baranowska-Kortylewicz, J., Di Luca, L., Meucci, G., R., Viacava, P., Van den Abbeele, A.D., Salvadori, P.A., Di Sacco, S., Adelstein, S.J., Bevilacqua, G., Kassis, A.I. Tumor targeting potential and metabolism of $5-\left[{ }^{125}\right.$ I $]$ iodo- $2^{\prime}-$ deoxyuridine injected intratumorally in patients with breast cancer. Ann New York Acad Sci, 698: 204-211, 1993.

[10]. Zuo, Z., Tam, Y., Diakur, J., Wiebe, L.I. Hydroxypropyl- $\beta$-cyclodextrin-flutamide inclusion complex: formulation, oral and intravenous pharmacokinetics of flutamide and the active metabolite, 2-hydroxyflutamide, in the rat. J Pharm Pharmaceut Sci. 5: 300-306, 2002. (www.ualberta.ca/ csps).

[11]. Wenz, G., Cyclodextrins as building blocks for supramolecular structures and functional units. Angew Chem Int Ed Engl, 33: 803-822, 1994.

[12]. Szejtli, J. Medicinal applications of cyclodextrins. Med Res Rev, 14: 353-386, 1994.

[13]. Seno, M., Lin, M., Iwamoto, K. Chromatic behavior of cyclodextrin complexes of nucleotides, nucleosides and their bases. J Chromatogr, 523: 293-299, 1990.

[14]. Eliseev, A.V., Schneider, H-J. Molecular recognition of nucleotides, nucleosides, and sugars by aminocyclodextrins. J Am Chem Soc, 116: 6081-6088, 1994.

[15]. Bergeron, R.J., Channing, M.A., McGovern, K.A., Roberts, W.P. Carboxylate anion binding in the cyclohexaamylose cavity: a steric and electronic evaluation. Bioorg Chem, 8: 263-281, 1979.

[16]. Hamilton, J.A. Structure of inclusion complexes of cyclomaltpheptaose (cycloheptaamylose): crystal structure of the 1-adamantanemethanol adduct. Carbohyd Res, 142: 21-37, 1985.

[17]. Eftink, M.R., Andy, M.L., Bystrom, K., Perlmutter, H.D., Kristol, D.S. Cyclodextrin inclusion complexes: studies in the variation of the size of acyclic guests. J Am Chem Soc, 111: 6765-6772, 1989.

[18]. McAlpine, S.R., Garcia-Garibay, M.A. Binding studies of adamantanecarboxylic acid and a naphthyl-bound $\beta$-cyclodextrin by variable temperature ${ }^{1} \mathrm{H}$ NMR. J Org Chem, 61: 83078309, 1996.

[19]. Gerzon, K., Kau, D. The adamantyl group in medicinal agents. 3. Nucleoside 5'-adamantoates. The adamantoyl function as a protecting group. J Med Chem, 10: 189-199, 1967.

[20]. Ho, Y.K., Hakala, M.T., Zakrzewski, S.F. 5-(1Adamantyl) pyrimidines as inhibitors of folate metabolism. Cancer Res,. 32: 1023-1028, 1972. 
[21]. Balzarini, J., De Clercq, E., Kaminska, B., Orzeszko, A. Synthesis and antiviral activity of some 5'-N-phthaloyl-3'-azido-2',3'dideoxythymidine analogues. Antiviral Chem Chemother, 14: 139-144, 2003.

[22]. Górska, A., Andrzejewska, M., Kamiński, J., Kazimierezuk, Z. Microwave-assisted synthesis of O'-adamantylated uracil-derived nucleosides. Nucleosides Nucleotides Nucleic Acids, 22: 1319, 2003.

[23]. Kazimierczuk, Z., Orzeszko, A., Sikorska, A. Studies on adanantylation of N-heterocycles and nucleosides. In Kisahuerek, M.V., Rosemeyer H. (Eds), Perspectives in Nucleoside and Nucleic Acid Chemistry. Wiley-VCH pp. 87-94, 2000.

[24]. Van Wik, A.J., Fourie, P.J., Bekker, P., Wood, S., Smith, K., Gerber, T., du Preez, J. Comparison of new ${ }^{99 m}$ Tc adamantane-IDA compounds with ${ }^{99 \mathrm{~m}}$ Tc BAT agents. In Billinghurst MW (Ed), Current Applications in Radiopharmacology. Pergamon Press, Toronto, pp. 27-34, 1986.

[25]. Loftsson, T., Brewster, M. E. Pharmaceutical applications of cyclodextrins. 1. Drug solubilization and stabilization. J Pharm Sci, 85: 1071-1025, 1996.

[26]. Higuchi, T., Connors, K.A. In Reilly, C.N. (Ed), Advances in Analytical Chemistry and Instrumentation. Wiley-Interscience, New York, Vol. 4, pp117-212, 1965.

[27]. Saenger, W., Cyclodextrin inclusion compounds in research and industry. Angew. Chem. Int. Ed. Engl, 19: 344-362, 1980.

[28]. Rekharsky, M.V., Goldberg, R.N., Schwarz, F.P., Tewari, Y.B., Ross, P.D., Yamashoji, Y., Inoue, Y. Thermodynamic and nuclear magnetic resonance study of the interactions of $\alpha$ - and $\beta$ cyclodextrin with model substances: phenethylamine, ephedrines, and related substances. J Am Chem Soc, 117: 8830-8840, 1995.

[29]. Carpenter ,T.O., Pettifor, J.M., Russell, R.M., Pitha, J.., Mobarhan, S., Ossip, M.S., Waine,r S., Anast, C.S. Severe hypervitaminosis A in siblings: evidence of variable tolerance to retinol intake. J Pediatr, 111: 507-12, 1984.

[30]. Stella, V.J., Rajewski, R.A. Cyclodextrins: their future in drug formulation and delivery. Pharm Res, 14:556-567, 1997.

[31]. Frijlink, H.W., Franssen, E.J., Eissens, A.C., Oosting, R., Lerk, C.F.., Meijer, D.K. The effects of cyclodextrins on the disposition of intravenously injected drugs in the rat. Pharm Res, 18: 380-384, 1991.

[32]. Frijlink, H.W., Eissens, A.C., Hefting, N.R., Poelstra, K., Lerk, C.F., Meijer, D.K. The effect of parenterally administered cyclodextrins on cholesterol levels in the rat. Pharm Res, 18: 9-16, 1991.

[33]. Dearden, J.C. Partitioning and lipophilicity in Quantitative Structure-Activity Relationships. Environ Health Perspect, 61: 203-228, 1985.

[34]. Cooper, D.A., Webb, D.R., Peters, J.C. Evaluation of the potential for Olestra to affect the availability of dietary phytochemicals. J Nutrition, 127: 1699S-1709S, 1997.

[35]. Rabenstein, D.L., Nakashima, T.T. Spin-echo Fourier transform nuclear magnetic resonance spectroscopy. Anal Chem, 51: 1465A-1474A, 1979. 